\title{
Optimal Growth with Corruption and under Development in Poorest Developing Countries
}

\author{
Diana Loubaki
}

IRES, Université Catholique de Louvain, 1348, Louvain-la-Neuve, Belgium

\begin{abstract}
This article investigates growth in an economic environment where prevail corruption and under development defined as the interaction between poverty on the one hand and the relationship between production and pollution on the other hand,. The purpose is to determinate requires conditions able to allow the economy converges to its sustainable optimal growth path. Whereas multiple equilibria due to corruption keeps the economy under developed and prevent it from the reach of the long run optimal sustainable growth path in which poverty is absent and average income levels at least equal to the threshold of the living standard, human capital accu mulation through learning by doing financed by the social planner with pollution income taxes introduces social insurance acquisition possibility and sustainability improvements. The model highlights suitable mechanics of growth sustainability and establishes that corruption partly prevents international Organizations' actions to reach their targets.
\end{abstract}

Keywords Poverty, Sustainability, Institution Imperfections, Multiple Equilibria, Strenghned Compound Inverted U-Shape, Corruption

\section{Introduction}

The aim of this artic le is to provide theoretical foundations of economic growth in the context of under development and corruption prevalence in Sub-Saharan Africa. As human capital accumu lation plays a great role in poverty eradication through productivity increase, social insurance acquisition through income increase does the same thing in sustainability improvements target confirmed by the inverted U-shape curve existence which indicates development sustainability achievement. The model also establishes that subsidies to low efficient firms may help poor economies get out of under development faster if corruption is absent.

Studies on corruption mostly show a decrease on economic capability to get out of under development or to converge to the long run growth[1]. Institution imperfection is evaluated to up to $55 \%$ in Latin America against $45-85 \%$ in Easter Asia and 80\% in Africa[2]-[3] . Mbaku emphasizes the important role that institutions have in corruption control and he recommends reconstructive democratic constitutions as a development tool[4]. In regard to the definition, corruption is a behaviour which deviates from formal duties of public role because of private regarding (personal, close family, private clique) pecuniary status gains; or violates rules against the exercise of certain types of private regarding influence[5]. The World Bank takes minimal

* Corresponding author:

diana.loubaki@laposte.net (Diana Loubaki)

Published online at http://journal.sapub.org/economics

Copyright (C) 2012 Scientific \& Academic Publishing. All Rights Reserved working definition which is the abuse of public office for private gains.

Corruption is motivated by poverty, productive capacities low technology and sustainability matters in developing countries while low labour productivity is mostly the resulting effect of the brain drain in Africa. According to National Commission of United Nations for Africa, $52 \%$ of people live actually with less than $1 \$$ per day ${ }^{1}$., extreme poverty represents $43 \%$ of urban population against $59 \%$ of rural population, poverty concerned 217 millions of people in 1987, 291 millions of people in 1998 and 310 millions of people in 1999 in level terms. World Health Organization reports that non cleaned water and air as well as pollution cause almost 300,000 deaths per-day in developing countries. Therefore, under development or the link between poverty on the one hand and the interaction between production and pollution on the other hand, characterize African economies and deserves a deeper study in order to establish conditions for growth and development economics.

The article uses the literatures of corruption and pollution connected to growth. On the one hand, the literature of corruption can be summarized in three approaches. The first research line addresses why policy makers, business leaders, and private citizens should concern themselves with the existence and elimination of corruption[6]. This research

\footnotetext{
1 This is the World Bank's global poverty count, which started with Montek Ahluwalia, Nicholas Carter and Hollis Chenery (1979), and became the dollars-a-day count in the World Development Report, 1990 was incorporated into international policy making and discussion via the Millenium Development Goals (MDG
} 
program focuses on the effect of policies and reforms on growth and macroeconomic stability and concludes that differences across countries in the quality of their institutions explain growth heterogeneity. The second research line addresses how and when political, social, and economic forces contribute in counter corruption drives, cost-benefit analysis on the part of a country's leaders in order to determinate existence or lack of an official policy[7]. The third approach focuses on what types of polic ies effectively counter corruption and highlight effective anticorruption instruments.

In a formal way, economic models the corrupt employee as a rational actor who decides whether to engage in corrupt activity by balancing the potential benefits against potential costs and consequences. Therefore, polic ies that worsen the consequences of engaging in corruption by increasing severity of punishment and like lihood of detection will lower corrupt activity. Bardhan argues that the frequency of corruption in a society changes the balance of its marginal costs and benefits for an official 1[8]. Klitgaard conceptualizes the opportunity for corruption in a formula: $\mathrm{C}$ $($ corruption $)=\mathrm{M}$ (monopoly) $+\mathrm{D}$ (discretion) $-\mathrm{A}$ (accountability)[9]. The opportunity for corruption is a function of the size of the rents under a public official's control(M), the discretion that official has in allocating those rents (D), and the accountability that official faces for his or her decisions (A). Other lines of research suggest a mixture of causal factors drawn from both political science and economic approaches. Ongoing empirical research of Kaufmann suggests that the determinants of corruption are complex because poor institutions, civil liberties, governance and economic policies, as well as other characteristics play an enabling role for corruption[10]. Along these interdisciplinary lines, the World Bank po ints to both institutional and economic policy factors which create a nourishing environment for corruption.

On the other hand, growth literature in connection to environment components begins seriously in the mid of the 1990s on the basis of the Meadows claim. The tool used is the Kuznets curve highlights by the U-shape inverted curve in theoretical models in order to specify that growth or development is sustainable. There are three approaches of growth connected to environment. The first approach studies the relationship between growth and pollution[11]-[16], the second approach links growth to natural resources[17] and the third approach links growth to climate change.[18]-[19] This article is connected to pollution in order to study Sub-Saharan Africa growth sustainability because natural resources and climate change don't affect human sustainability more than pollution does.

This study models the economic environment closely to the literature of corruption in order to establish growth and sustainability foundations in poor countries. The economic agents of this macroeconomic analysis are consumers, firms and a social planner. The social planner corrects market failures. Both firms and consumers are divided in two parts. Some firms are efficient, some other are not. Equivalently some agents are poor and some others are not. The social planner's intervention is legitimated by the fact that pollution hurts the poor agent's utility function whom he finances human capital accumulation with the revenues from taxes on emissions, $G$ he got from non efficient firms which he transfers to most efficient firms in order to organize knowledge acquisition through learning by doing, while production is taking place in order to allow the poorest agents get a social insurance through income increase. The least efficient firm $N_{l}$ has a probability $p$ to face an honest budget collector staff and a probability $q=1-p$ to face a corrupt budget collector staff who accept to negotiate about changes on the tax rate set by the social planner. Since $q \neq 0$ there exist multiple equilibria which highlight institution's failure in the developing country and explain at the same time why the economy remains kept in a poverty trap as well as weak foreign aids impact on the economy. If $q=0$, the economy converges to its unique optimal sustainable development path on which, the wage rate income $w(t)$ equals at least the threshold standard of living, $w^{*}$ i.e $w(t) \geq$ $w^{*}$. Then the agent can be covered by a social insurance i.e $v(t) \neq 0$.

The results obtained are first, institution imperfections create growth instability and increase the difficulties to predict its evolution over time. Second, subsidies received from international donors may lift the econo my fro m poverty trap if corruption is not introduced. Subsidies to firms are more efficient for growth sustainability and development than fiscal policy based on revenues from emission taxes proposed by the model. International aids may achieve their target without corruption prevalence. Third, corruption is unable to boost the economy to its long run sustainable path, tools control for perfect institution may must be established in order to lift the economy to optimal growth.

The article presentation is organized like follow, section2 sets the model, section 3 gives the market equilibrium conditions and sections 4 discusses the optimal growth sustainability program for development and poverty eradication. Finally section 5 concludes on the model.

\section{The Model}

Consider a developing country where exist a constant labour force at each period, $L(t)=L$ and $N$ firms divided in two parts to produce the same homogenous consumption good using technology differentials indexed by, $z(t) \epsilon[0,1]$. If $z<1$, the technology used is cleaned and generates high (efficient) and ecological per-capita production. Otherwise if $z=1$, the technology used produces consumption goods in the dirtiest way.

\subsection{Production Sector}

Lemma 1: Let $\mathrm{z}$ be an index of technology inside the range ]0,1]. Then, technology $\phi(z)$ chosen by the two kinds of firms differs in their technological sophistication i.e the respective non rival technology chosen by the High-Tech 
sector of production and the Low-Tech sector of production are

$$
\begin{array}{cc}
\phi(z)=\frac{1}{1-z} & 0<\mathrm{z}<1 \\
\phi(z)=\delta & \mathrm{z}=1
\end{array}
$$

$\delta$ is a parameter such that $0<\delta \preccurlyeq 1$ (see the appendix for proof)

The production functions of the firms $N_{1}$ and $N_{2}$ are specified according to Eicher where firm $N_{1}$ is associated to Low-Tech production sector because it uses old and discarded technology $\phi(1)=\delta$ and a labour force stock $L_{1}$ endowed with a basic hu man capital level, $h_{o}$. [20] In contrast, firm $N_{2}$ is associated to High-Tech production sector which uses new technology $\phi(z)=1 / 1-z$ and skilled labour force stock $L_{2}$ endowed with at least the average human capital level $h_{t}$.

The Low-Tech production function is expressed by equation (3) i.e

$$
Y_{1}(t)=\delta h_{0}^{\mu_{1}} L_{1}(t)^{\gamma_{1}}
$$

$\delta>0, \mu_{1}+\gamma_{1}=1$ is the sum of the elastic ity of basic human capital and labour force stocks used where $0<\mu_{1}, \gamma_{1}<1$. The Low-Tech sector can't improve its productivity if no investments are done both in cleaner technologies and in human capital accumulation.

The High-Tech production function is expressed by equation (4) i.e

$$
Y_{2}(t)=(1-z)^{-1} h(t)^{\mu_{2}} L_{2}(t)^{\gamma_{2}}
$$

$0<\mu_{2}, \gamma_{2}<1$ and $\mu_{2}+\gamma_{2}=1$ is the sum of the elasticity of human capital and the of the labour force.

Production of the consumption goods takes place in perfectly competitive sectors. Rewriting the production functions (3) and (4) in intensive forms and setting $k_{1}(t)=h_{o} / L_{1}(t)$ and $k_{2}(t)=h(t) / L_{2}(t)$, per capita production function of the Low-Tech and the High-Tech are respectively expressed by (5) and (6) i.e

$$
\begin{aligned}
& y_{1}(t)=\delta k_{1}(t)^{\mu_{1}} \\
& y_{2}(t)=(1-z)^{-1} k_{2}(t)^{\mu_{2}}
\end{aligned}
$$

Where $y_{1}(t)=Y_{1}(t) / L_{1}(t)$ and $y_{2}(t)=Y_{2}(t) / L_{2}(t)$

Profit maximization yields the standard first order conditions i.e the wage rate income equals the marginal product of the High-Tech sector, $w^{H}(t)$ and the Low-Tech sector, $\mathrm{w}^{\mathrm{L}}(\mathrm{t})$ respectively expressed by (7) and (8)

$$
\begin{gathered}
w^{H}(t)=\gamma_{2}(1-z)^{-1} k_{2}(t)^{\mu_{2}} \geq w^{*} \\
w^{L}(t)=\delta \gamma_{1} k_{1}(t)^{\mu_{1}}<w^{*}
\end{gathered}
$$

Where $w^{*}$ is the threshold of the living standard, when an agent's wage rate inco me is below $w^{*}$, then he is poor.

Each firm of the both categories $N_{1}$ and $N_{2}$ determinates its own interest rate when maximizing its profit which we assume to be the respective human capital hiring costs $r_{1}$ for the firms $N_{1}$ and $r_{2}$ for the firms $N_{2}$ where $r_{1} \neq r_{2}$ i.e

$$
r_{1}=\delta \mu_{1} k_{1}^{\mu_{1}-1}
$$

$$
r_{2}=(1-z)^{-1} \mu_{2} k_{2}^{\mu_{2}-1}
$$

If $r_{1}=r_{2}$, it yields the "catching up" equilibrium condition of the firms $N_{1}$ and $N_{2}$ structure expressed by the condition $k_{1}=k_{2}=k$ where $k=\left[(1-z) \delta \mu_{1} / \mu_{2}\right]^{1 / \mu_{2}-\mu_{1}}$

If $r_{1}<r_{2}$, we join Solow neoclassical result with respect to absolute convergence where marginal benefit of per-capita capital stock, $k_{1}$ is higher than that of per-capita capital stock $k_{2}$. Thus, with technological improvements, the firms $N_{1}$ grow faster than the firms $N_{2}$. In the long-run, there is absolute convergence of the firms [21].

If $r_{1}>r_{2}$, we join the AK result with respect to conditional convergence. The marginal benefit of per-capita capital stock, $k_{1}$ is lower than the marg inal benefit of per-capita capital stock $k_{2}$. Thus, the firms $N_{1}$ are more sensitive to collapse or the ending of activities than the firms $N_{2}$, the firms $N_{1}$ can't grow faster than the firms $N_{2}$. In the long-run, the firms are not the same because the marg inal benefit of capital is no more decreasing like in the previous case.

\subsection{The Capital Stocks Dynamics}

In conformity with national income accounting conventions, it is useful to define an accounting measure of per-capita stock of capital as cumulative forgone output. Thus $k_{1}(t), k_{2}(t)$ and $h(t)$ involve according to the following rule i.e

$$
\begin{gathered}
k_{1}(t)=\delta k_{1}(t)^{\mu_{1}}-c_{1}(t)-\hat{\tau} e(t) \\
\dot{k}_{2}(t)=(1-z)^{-1} k_{2}(t)^{\mu_{2}}-c_{2}(t)+\hat{\tau} e(t) \\
\dot{h}(t)=\theta_{h} v(t)(1-z)^{-1} h(t)
\end{gathered}
$$

$\hat{\tau}$ is a positive per unit of emissions tax rate, $e_{1}(t)=E(t) / L_{1}(t)$ is a per-capita standard emissions of the firms $N_{1}, \theta_{h}>0$ is the productivity of human capital.

\subsection{Preferences}

\subsubsection{The Poor Agent}

The intertemporal utility function of the poor agent is expressed over consumption, $c_{1}$ and pollution, $x_{1}$. Pollution hurts the poor agent as expresses his utility function, (14). The social planner sets a bound on the dirtiest technology that may be used in respect to pollution generated. Therefore, the utility function of the poor agent is expressed by $(14)^{2}$ i.e

$$
U\left(c_{1}(t), x_{1}(t)\right)=\int_{0}^{\infty} e^{-\rho t}\left[\left(\frac{c_{1}(t)^{1-\sigma_{1}}-1}{1-\sigma_{1}}\right)-B \frac{x_{1}(t)^{\varsigma}}{\varsigma}\right] d t(14)
$$

$\rho>0$ is the intertemporal discount rate, $\zeta$ is pollution intensity and $\sigma_{1}$ is the inverse of the elasticity of substitution.

If $B>0$ (the parameter of the impact of pollution in the utility function of the poor agent) and $\zeta>1$ then, the firms $N_{1}$ pollution function $x_{1}(t)$ highly hurts the utility of the poor

\footnotetext{
${ }^{2}$ This function is the same as the one used by Stockey (1998)
} 
agent. The second term of the utility function is the marginal cost of pollution and the first term of the utility function is the marginal benefit of production (consumption). For a fixed $\zeta$, preferences of the poor agent are increasing if $\sigma_{1}<1$, are decreasing if $\sigma_{1}>1$ and are constant if $\sigma_{1}=1$. Assuming that poor agent spends his whole per-capita wage rate income in consumption goods i.e $w^{L}(t)=c_{1}(t)$ then $\delta k_{1}(t)^{\mu_{1}}=c_{1}(t) / \gamma_{1}=x_{1}$ therefore, the intertemporal utility function depends on per-capita consumption only, expressed by (15) i.e

$$
U\left(c_{1}(t)\right)=\int_{0}^{\infty} e^{-\rho t}\left[\left(\frac{c_{1}(t)^{1-\sigma_{1}}-1}{1-\sigma_{1}}\right)-B \frac{\left[\delta c_{1}(t) / \gamma_{1}\right]^{\varsigma}}{\varsigma}\right] d t
$$

The optimization of the intertemporal utility function, (15) yields per-capita equilibrium consumption $c_{1}{ }^{*}$ and per-capita pollution level $x_{1}{ }^{*}$ i.e

and

$$
c_{1}^{*}=\left[B^{-1}\left(\gamma_{1} / \delta\right)^{\varsigma}\right]^{1 / \sigma_{1}+\varsigma-1}
$$

$$
x_{1}^{*}=\gamma^{-1}\left[B^{-1}\left(\gamma_{1} / \delta\right)^{\varsigma}\right]^{1 / \sigma_{1}+\varsigma-1}
$$

From $\delta k_{1}(t)^{\mu_{1}}=c_{1}(t) / \gamma_{1}=x_{1}$ per-capita pollution growth rate of the firms $N_{1}$ is $\frac{x\left(y_{1}\right)}{x\left(y_{1}\right)}=\mu_{1}\left(\frac{0}{k_{1}} k_{k_{1}}\right)$. Substituting per-capita capital dynamics evolution by its value and setting the total revenues from emissions taxes such that, $G=\hat{\tau}$ e, then pollution growth rate is

$$
\frac{\dot{x}\left(y_{1}\right)}{x\left(y_{1}\right)}=\mu_{1}\left(\frac{\delta}{k_{1}^{1-\mu_{1}}}-\frac{\left[B^{-1}\left(\gamma_{1} / \delta\right)^{\zeta}\right]^{1 / \sigma_{1}+\varsigma^{-1}}+G}{k_{1}}\right)
$$

The calibration of the firms $N_{2}$ pollution growth rate such as following for examp le i.e

$\alpha=0.8, \zeta=1.5, \mu_{2}=0.5, \mu=0.2, \gamma_{2}=0.5, \quad G=B=1, \quad z=0.5$, $\sigma_{2}=0.5$ and the simulation determinate the $\mathrm{U}$ inverted curve (figure 1)

Poverty function is defined such that

$$
P=\frac{\partial U\left(c_{1}^{*}, x_{1}^{*}\right)}{\partial t}=c_{1}^{-\sigma_{1}}-\frac{x_{1}}{x_{1}}
$$

then its expression is

$$
P=\left[\left(B^{-1}\left(\gamma_{1} / \delta\right)^{\varsigma}\right) \frac{1}{\sigma_{1}+\varsigma^{-1}}\right]^{-\sigma_{1}}-\frac{x_{1}}{x_{1}}
$$

Proposition 2: The economy converges to its unique optimal sustainable development path without poverty if and only if, there exists a couple equilibrium variables of per-capita capital stock and revenues from emission taxes, $\left(k_{1}{ }^{*}, G^{*}\right)$ such that

$$
k_{1}^{*}=\left[\delta \mu_{1}^{2} \psi\right]^{1 / 1-\mu_{1}}
$$

$$
\begin{gathered}
G^{*}=\left[\delta \mu_{1}^{2} \psi^{\mu_{1}}\right]^{\frac{1}{1-\mu_{1}}}-\left(\mu_{1} \psi\right)^{-1}+ \\
{\left[\left(\delta \mu_{1}^{3-\mu_{1}}\right)^{1 / 1-\mu_{1}} \psi \frac{\left(2-\mu_{1}\right) \sigma_{1}+\left(1-\mu_{1}\right)\left(\sigma_{1}+\varsigma-1\right)}{\sigma_{1}\left(1-\mu_{1}\right)}\right]^{-1}} \\
\psi=\left[B^{-1}\left(\gamma_{1} / \delta\right)^{\varsigma}\right]^{\frac{\sigma_{1}}{\sigma_{1}+\varsigma^{-1}}}
\end{gathered}
$$

Setting $P=0 \quad$ (see the appendix for proof) i.e poverty eradication yields revenues from taxes on emissions $G$ in function of per-capita stock of capital i.e $G=G\left(k_{1}\right)$. Then solving $\frac{\partial G^{*}}{\partial k_{1}^{*}}=0$ yields $k_{1}^{*}=\left[\delta \mu_{1}^{2}\left[B^{-1}\left(\gamma_{1}\right)^{\varsigma}\right]^{\sigma_{1 / \sigma_{1+\varsigma-1}}}\right]^{1 / 1-\mu_{1}}$

Substituting the expression of per-capita capital equilibrium found just above in the expression of $G=G\left(k_{1}\right)$ yields the both variables in terms of parameters only i.e equations (18) and (19). The inverted U-shape exists, poverty may be eradicated and sustainability improved over time.

\subsubsection{The Non Poor Agent}

The non poor agent wage rate income, $w^{H}(t)$ allows the agent contracts a social insurance $v(t)$ like each agent who works in the firms $N_{2}$.. Indeed, the utility function of the non poor agent is expressed by (20) i.e

$$
U\left(c_{2}(t), v(t)\right)=\int_{0}^{\infty}\left[\frac{\left(c_{2}(t)^{\alpha} v(t)^{\beta}\right)^{1-\sigma_{2}}-1}{1-\sigma_{2}}\right] d t
$$

$\alpha>0, \beta>0$ and $\alpha+\beta=1, \sigma_{2}$ is the inverse of the elasticity of substitution between consumption and social insurance, $\rho>0$ is the intertemporal discount rate.

The budget constraint of the agent, $w^{H}(t)=c_{2}(t)+v(t)$ leads to $(1-z)^{-1} \gamma_{2} k_{2}(t)^{\mu_{2}}=c_{2}(t)+v(t)$. Optimization of the utility function subject to the budget constraint yields the equilibrium per-capita consumption $c_{2}{ }^{*}(t)$ and the equilibrium per-capita social insurance i.e $c_{2}(t)^{*}=\alpha(1-z)^{-1} \gamma_{2} k_{2}(t)^{\mu_{2}} \quad$ and $v(t)^{*}=\beta(1-z)^{-1} \gamma_{2} k_{2}(t)^{\mu_{2}}$ where $\phi \quad(z)=(1-z)^{-1}$ and $0<z<1$.

The firms $N_{2}$ per-capita pollution function $x\left(y_{2}\right)=y_{2} z^{\varepsilon}$ implies $\dot{x}\left(y_{2}\right)=\left(z^{\varepsilon} / 1-z\right) k_{2}{ }^{\mu_{2}}$ is a decreasing function in per-capita capitalstock. Thus the firms $N_{2}$ pollution function growth rate is $\frac{\dot{x}\left(y_{2}\right)}{x\left(y_{2}\right)}=\mu_{2}\left(\frac{\mathfrak{k}_{2}}{k_{2}}\right)$. Substituting per-capita growth rate of the capital stock of the firms $N_{2}$ by its value, yields the final analytical pollution type 2 expression (21) i.e

$$
\frac{x\left(y_{2}\right)}{x\left(y_{2}\right)}=\mu_{2}\left(1-\alpha \gamma_{2}\right)(1-z)^{-1} k_{2}^{\mu_{2}-1}+\mu_{2} \frac{G}{k_{2}}
$$


The calib ration of the firms $N_{2}$ pollution growth rate such as following for example i.e $\alpha=0.8, \zeta=1.5, \mu_{2}=0.5, \mu=0.2$, $\gamma_{2}=0.5, G=B=1, z=0.5, \sigma_{2}=0.5$. Then, the simulation of the firms $N_{2}$ pollution growth rate displays a decreasing curve

(see figure2). U-shape added to a half inverted U-shape, yields strenghned compound inverted U-shape.

Proposition3: setting pollution evolution to zero i.e $\dot{x}\left(y_{2}\right)=0$ yields the equilibrium per-capita stock of capital leading to pollution eradication, $k_{2}{ }^{*}$ such that $k_{2}^{*} \approx\left[\left(\frac{\mu_{2}}{\alpha \gamma_{2}-1}\right)(1-z) G^{*}\right]^{1 / \mu_{2}}$

Where $G^{*}$ expression is already determinate above

Proposition $4^{3}$. The thresholds of production $y^{*}$, of the wage rate income $w^{*}$ and of human capital level $h^{*}$ are expressed by equations (23)- (25) i.e

$$
\begin{gathered}
y^{*}=z^{1 / \mu_{2}}\left(\mu_{2} / \alpha \gamma_{2}\right) G^{*} \\
w^{*}=\gamma_{2}\left(\mu_{2} / \alpha \gamma_{2}\right) G^{*} \\
h^{*}=\left[\beta \theta_{h} \mu_{2} / \alpha(1-z)\left(u+\theta_{h}\right)\right] G^{*}
\end{gathered}
$$

See the appendix for proof

\section{The Optimal Problem}

$$
\begin{gathered}
\operatorname{Max}\left\{\int_{0}^{\infty} e^{-\rho t}\left[\begin{array}{c}
\frac{c_{1}(t)^{1-\sigma_{1}}-1}{1-\sigma_{1}}-B \frac{\left(\gamma_{1}^{-1} c_{1}(t)\right)^{\varsigma}}{\varsigma} \\
+\frac{\left(c_{2}(t)^{\alpha} v(t)^{\beta}\right)^{1-\sigma_{2}}-1}{1-\sigma_{2}}
\end{array}\right] d t\right. \\
\circ \\
k_{1}(t)=\delta k_{1}(t)^{\mu_{1}}-G-c_{1}(t) \\
k_{2}(t)=(1-z)^{-1} k_{2}(t)^{\mu_{2}}+G-c_{2}(t) \\
h(t)=\theta_{h}(1-z)^{-1} v(t) h(t)
\end{gathered}
$$

According to the Optimal Control Theory, the Hamiltonian, $H$ is expressed such as

$$
\begin{gathered}
H=\left[\frac{c_{1}(t)^{1-\sigma_{1}}-1}{1-\sigma_{1}}-B \frac{\left(\gamma_{1}^{-1} c_{1}(t)\right)^{s}}{\varsigma}+\frac{\left(c_{2}(t)^{\alpha} v(t)^{\beta}\right)^{1-\sigma_{2}}-1}{1-\sigma_{2}}\right]+ \\
\lambda_{1}\left[\delta k_{1}(t)^{\mu_{1}}-G-c_{1}(t)\right]^{+} \lambda_{2}\left[(1-z)^{-1} k_{2}(t)^{\mu_{2}}+G-c_{2}(t)\right] \\
+\lambda_{3} \theta_{h}(1-z)^{-1} v(t) h(t)
\end{gathered}
$$

Definition 1: The sustainable development path is defined by a three components vector $\left(g_{1}, g_{2}, g_{v}\right)$ i.e

\footnotetext{
${ }^{3}$ The aim of the economic indicators or the thresholds of crucial variables is to evaluate the way poverty and environmental degradation can be improved in order to establish Pareto optimality in correcting failures introduced by the market based economy
}

$$
\begin{gathered}
g_{1}=\frac{1}{\sigma_{1}+\varsigma-1}\left(\rho-\frac{1}{\mu_{1} \psi}\right) \\
g_{2}=\frac{1-\beta\left(1-\sigma_{2}\right)}{\sigma_{2}}\left[\mu_{2}^{2}(1-z)^{-1 / \mu_{2}}\left(\frac{\alpha \gamma_{2}}{G^{*}}\right)^{1-\mu_{2} / \mu_{2}}-\rho\right] \\
g_{v}=\frac{1-\beta\left(1-\sigma_{2}\right)}{\sigma_{2}}\left[\mu_{2}^{2}(1-z)^{-1 / \mu_{2}}\left(\frac{\alpha \gamma_{2}}{G^{*}}\right)^{1-\mu_{2} / \mu_{2}}-\rho\right] \\
-\left(\frac{\mu_{2}}{1-z}\right)\left[\left(\frac{\alpha \gamma_{2}}{(1-z) \mu_{2} G^{*}}\right)\right]^{1-\mu_{2} / \mu_{2}}
\end{gathered}
$$

Where

$g_{1}=\frac{c_{1}}{c_{1}}$ is the economic growth rate of the firms $\mathrm{N}_{1}$, the growth rate of the efficient firms is $g_{2}=\frac{c_{2}}{c_{2}}$ and $g_{v}=\frac{v}{v}$ is the environmental quality growth rate

Definition 2: the optimal sustainable development path where the economic growth and the environmental quality grow at the same rate i.e $\left(g_{1}, g_{2}, g_{v}\right)$ and $g_{2}=g_{v}$ exists (See the appendix for proof)

\section{Results and Discussions}

$1^{\text {st }}$ results category: the tax rate set is the sum of the payment probability conditioned by the government staff behaviour, where he has a probability $p$ to be honest and $q$ to be corrupt added to a corruption degree expressed by $s$ i.e $: \tau$ $=p r_{1}+q(1-s) r_{1}=(q+p) r_{1}-q s r_{1}=r_{1}-q s r_{1}$ y ields $\hat{\tau}=(1-q s) r_{1}$.

If $q=0^{4}$, i.e corruption is absent, there exist a unique optimal sustainable development path expressed by a couple of functions, $\left(G, k_{2}\right)$ such that, $G=G^{*}$ and $k_{2}=k_{2}{ }^{*}$, therefore,

because $r_{1}=\tau$ and $g_{2}=g_{v}$, the poor economy converges to its optimal sustainable development path without poverty and pollution ${ }^{5}$ due to the fact that $p=1$, then $\hat{\tau}=r_{1}=$ $\delta \mu_{1} k_{1}^{\mu_{1-1}=1 / \psi}$, therefore

$$
\begin{aligned}
G=G^{*} & =\left[\delta \mu_{1}^{2} \psi^{\mu_{1}}\right]^{\frac{1}{1-\mu_{1}}}-\left(\mu_{1} \psi\right)^{-1}+ \\
& {\left[\left(\delta \mu_{1}^{3-\mu_{1}}\right)^{1 / 1-\mu_{1}} \psi \frac{\left(2-\mu_{1}\right) \sigma_{1}+\left(1-\mu_{1}\right)\left(\sigma_{1}+\varsigma_{-1}\right)}{\sigma_{1}\left(1-\mu_{1}\right)}\right]^{-1} }
\end{aligned}
$$

\footnotetext{
${ }^{4}$ Proof of existence and stability of sustainable growth path (see the appendix) $g_{v}=g_{2} \quad$ yields $\sigma_{2}=1-1 / 2 \alpha$ then $\mathrm{g}_{1} \rightarrow \mathrm{g}_{2}$ if and only if $r_{1}=\left[\sigma_{1}+\zeta-1\right] /[1+\beta(2 \alpha-1) / 4 \alpha] r_{2}=\Delta r_{2}$ for simplicity, we assume $r_{1} \simeq r_{2}$
} 


$$
\mathrm{k} 2=k_{2}^{*}=\left[\left(\frac{\mu_{2}}{\alpha \gamma_{2}}\right)(1-z) \hat{\tau} e\right]^{1 / \mu_{2}}
$$

If $q \neq 0$ i.e $p \neq 1$, the optimal sustainable development path is not pareto efficient because, there exist multiple equilibria due to negotiation between the firms $\mathrm{N}_{1}$ and the budget collector staff, the bias introduced leads to, $\mathrm{G} \neq \mathrm{G}^{*}$ and $\mathrm{k}_{2} \neq \mathrm{k}_{2}{ }^{*}$. The nature of the non optimality depends on the favour obtained by the firms from the budget collector staff expressed by $\mathrm{s}$.

If $s=1$, the firms are checking out the honesty of the staff budget collector, $\hat{\tau}=(1-\mathrm{sq}) \mathrm{r}_{1}=\mathrm{pr}_{1}{ }^{6}$, therefore $\hat{\tau}=\mathrm{p}(1 / \psi)$ is a preliminary corruption activity where e is a per-unit emission stock. The success of the policy depends on the value of the probability, if $\mathrm{p}$ is close to 1 then the optimal sustainable development path is reached because negotiations between the staff and the non efficient firm fail, thus,

$$
\begin{aligned}
G= & {\left[\delta \mu_{1}^{2}(1 / \hat{\tau})^{\mu_{1}}\right]^{\frac{1}{1-\mu_{1}}}-\left(\mu_{1}(1 / \hat{\tau})\right)^{-1}+} \\
& {\left.\left[\left(\delta \mu_{1}^{3-\mu_{1}}\right)^{1 / 1-\mu_{1}}(1 / \hat{\tau})\right]^{\frac{\left(2-\mu_{1}\right) \sigma_{1}+\left(1-\mu_{1}\right)\left(\sigma_{1}+\varsigma-1\right)}{\sigma_{1}\left(1-\mu_{1}\right)}}\right]^{-1} }
\end{aligned}
$$

(34) converges to $\mathrm{G}^{*}$

$$
\text { and } \mathrm{k}_{2}{ }^{7}=\left[\frac{\mu_{2}}{\alpha \gamma_{2}}(1-z)\left(\frac{e}{\psi}\right)\right]^{1 / \mu_{2}} \text { (35) converge to } \mathrm{k}_{2}{ }^{*}
$$

where $\hat{\tau}=1 / \psi$.

Otherwise, if $p$ is close to 0 , the optimal sustainable development path can't be reached because negotiations between the staff and the non efficient firm achieved and then, $\mathrm{G}$ converge to $0<\mathrm{G}^{*}$ and $\mathrm{k}_{2}$ converge to $0<\mathrm{k}_{2}{ }^{*}$.

If $0<\mathbf{s}<1$, there exists a positive parameter $\mathrm{b}$ where

$0<\mathrm{b}<1$ such that $\tau=(1-\mathrm{b}) / \psi$ there is funds eviction where $q \neq 0$ i.e funds for development sustainability and poverty eradication are only partly provided. Indeed we have,

$$
\begin{aligned}
G & =\left[\delta \mu_{1}^{2}(1-b / \hat{\tau})^{\mu_{1}}\right]^{\frac{1}{1-\mu_{1}}}-\left(\mu_{1}(1-b / \hat{\tau})\right)^{-1}+ \\
& {\left[\left(\delta \mu_{1}^{3-\mu_{1}}\right)^{1 / 1-\mu_{1}}(1-b / \hat{\tau})^{\frac{\left(2-\mu_{1}\right) \sigma_{1}+\left(1-\mu_{1}\right)\left(\sigma_{1}+\varsigma-1\right)}{\sigma_{1}\left(1-\mu_{1}\right)}}\right]^{-1} \prec G^{*} }
\end{aligned}
$$

and

$$
{ }^{6} \operatorname{pr}_{l}=p\left\lfloor\delta \mu_{1}\left(\delta \mu_{1}^{2} \psi\right)^{\mu_{1}-1 / 1-\mu_{1}}\right\rfloor=p / \psi
$$

\footnotetext{
${ }^{7}$ See proposition 4
}

$$
k_{2}=\left[\frac{\mu_{2}}{\alpha \gamma_{2}}(1-z)(1-b)\left(\frac{e}{\psi}\right)\right]^{1 / \mu_{2}}<k_{2}{ }^{*} .
$$

The economy is unable to achieve his long-run optimal sustainable development path without poverty. Indeed, there is almost no change of the production structures of the firms $N_{1}$ because incentives to imp rove the production process are too low, pollution and/ or poverty keep increasing.

If $-1<s<0, \hat{\tau}=(1+b) / \psi$, this situation reveals a special economic policy deal and can be viewed in two different ways with respect to the impact on sustainable development, we have

$$
\begin{gathered}
G=\left[\delta \mu_{1}^{2}(1+b / \hat{\tau})^{\mu_{1}}\right]^{\frac{1}{1-\mu_{1}}}-\left(\mu_{1}(1+b / \hat{\tau})\right)^{-1}+ \\
{\left[\left(\delta \mu_{1}^{3-\mu_{1}}\right)^{1 / 1-\mu_{1}}(1+b / \hat{\tau})^{\left.\frac{\left(2-\mu_{1}\right) \sigma_{1}+\left(1-\mu_{1}\right)\left(\sigma_{1}+\varsigma-1\right)}{\sigma_{1}\left(1-\mu_{1}\right)}\right]^{-1} \succ G^{*}}\right.} \\
k_{2}=\left[\frac{\mu_{2}}{\alpha \gamma_{2}}(1-z)(1+b)\left(\frac{e}{\psi}\right)\right]^{1 / \mu_{2}}>k_{2}^{*}
\end{gathered}
$$

Two interpretations can be given:

First, the budget is higher than the expected value because firms may have received subsidies from international donors for examp le in order to improve the production process. Non efficient firms are able to change their production structure without high investment costs, thus are no more taxed by the government and don't need dealing with corruption which reduce pressure in regard both to the competitive environment as well to the social planner. Subsidies on non efficient firms increase the speed of convergence of the economy to optimal sustainable development path.

Second, the social planner discovers corruption activity and asks Low-Tech firms to give back funds not paid. Indeed, the surplus viewed is only debt contracted by most polluting firms to the government or retards on bill payments. Thus, low tech firms are out of law and must give back the money $k e p t$ in order to establish optimality. Costs are too high and firms can't pay. The social planner must order the cease of their activities to punish corruption activity if so, some firms $N_{1}$ stop their activ ities a lso because costs become higher than profit, the sustainability imp roves as well as poverty is under control.

Conclusion: multiple equilibria due to corruption come from non accomplishment of the law, Optimal fiscal policy is efficient if the required conditions are filled. Otherwise, Institutions imperfections explain under development as well as poverty. Firms' subsidies for production improvements are more efficient for sustainable development and pollution eradication than fiscal policy on emissions. Negotiation between firms and staff budget collector should be punished by the law.

2 de results category 
We've seen that, $q=0$, the tax rate $\hat{\tau}=r_{1}$ indeed $G=G^{*}$ and $k_{2}=k_{2}{ }^{*}$ therefore, now we know that it leads to $g_{1}=\frac{1}{\sigma_{1}+\varsigma-1}\left[\rho-1 / \mu_{1} \psi\right]=g_{1} *$ and this situation serves as a reference of the efficiency of the economic policy conducted by the social planner in regard to the biased situations i.e when $q \neq 0$

If $q \neq 0$, the tax rate $\hat{\tau} \neq r_{1}$ indeed $G \neq G^{*}$ and $k_{2} \neq k_{2}{ }^{*}$ therefore

If $-1<s<0$ then $G>G^{*}$ and $k_{2}>k_{2}{ }^{*}$ indeed $g_{1}=\frac{1}{\sigma_{1}+\varsigma-1}\left(\rho-\frac{\hat{\tau}}{\mu_{1}(1+b)}\right)>g_{1 *}$ if there is foreign aids introduction or fiscal policy based on investment support of the firms, growth accelerates. Otherwise, if this case corresponds to debt contraction because of corruption, then $g_{l}<g_{l} *$ emis sions still too high than the expected level, the economy can't converge to the optimal sustainable development path because funds are not high enough to support professional training. Emissions remain too high to allow growth increases. Poor agents are unable to change their social status because of imperfect institutions. Most of polluting firms pursue their activities, thus poverty under development and corruption maintain.

$g_{1}=\frac{1}{\sigma_{1}+\varsigma-1}\left(\rho-\frac{\hat{\tau}}{\mu_{1}(1-b)}\right)$, in this case, the bias introduced leads to low funds and high pollution, thus continuous corruption and low growth.

$g_{1}=\frac{1}{\sigma_{1}+\varsigma-1}\left(\rho-\frac{\hat{\tau}}{\mu_{1} p}\right)$. The bias introduced depends on the value of the probability $p$ such that the economic policy is completely ruled-out since $p$ converges to 0 mean ing that $q$ converges to $l$ or extreme eviction, in that case we have $g_{1}$ converges to 0 . There is no capability for the social planner to make the economy getting out of poverty trap. If $p$ converges to 1 , then $g_{1}=\frac{1}{\sigma_{1}+\varsigma-1}\left(\rho-\frac{\hat{\tau}}{\mu_{1}}\right)$ converge to $g_{1} *$, development and sustainability are imp roved.

\section{Conclusions}

Fiscal policy based on emissions taxation can allow the poor country's economy get out of poverty trap if required conditions are filled i.e there is no corruption for underdevelopment to cease and sustainability to improve. If institutions are imperfect, the poor country's economic path takes more time to reach optimal locus without poverty even using subsidies on firm financial support. The model examined the modality for the poor economy where prevail corruption and under development to overcome growth absence and establish optimality and finds that: productivity increase due to human capital increase may open up social insurance possibility and sustainability increase, firms under development capacities are nourished by negotiation which creates non rational choices and poverty prevalence. Under development and poverty motivate corruption and alter sustainability. Examining the instant in time when negotiations hold between the government staffs and firms yields to economic policy interruption and show that it is difficult to prove corruption existence through data, analytical models are suitable to study hidden behaviours like corruption because of data unused for its understanding.

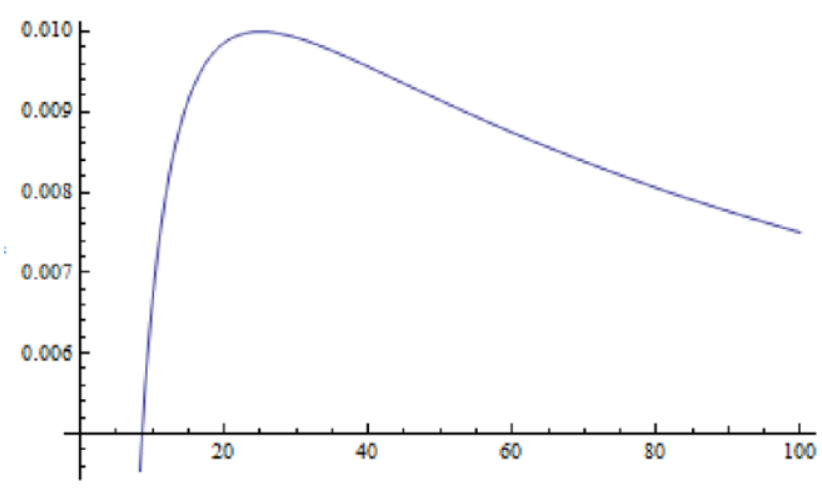

Figure 1. the inverted U-shape provided by poor solution utility

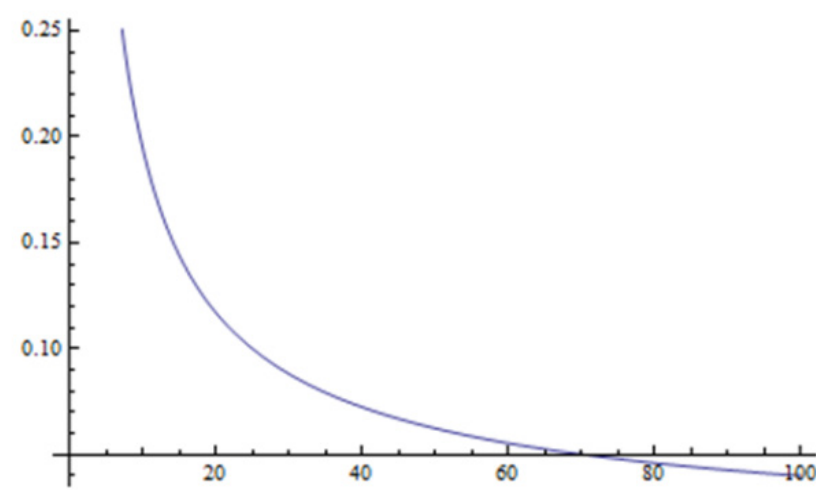

Figure 2. Half inverted U-shape highlights by non poor agent strategy

\section{ACKNOWLEDGEMENTS}

The author wishes to thanks the Editor and the anonymous referees of the journal, errors and misunderstandings are solely mines.

\section{APPENDIX}


Proof of Lemma 1

Following Stockey (1998), the firms produce $y(t)$ using the technology $\phi(z)$ which generates a level of pollution $x(t)=y(t) z(t)^{\varepsilon}$. Therefore, potential production is $y(t) \phi(z(t))$ where $\phi($,$) is the technology function which is increasing$ and convex on actual production i.e $\phi^{\prime}(\mathrm{z})>0, \phi^{\prime \prime}(\mathrm{z})>0$ and $\phi^{\prime}(1)=\delta \preccurlyeq 1$. Then, the effective production function is $E f f(y(t))=y(t) \phi(z(t))-y(t) z(t)^{\varepsilon}$..The choice of the technology is given by the equilibrium condition provided by the optimization of the effective production function with respect to the index of technology i.e: $\frac{\partial E f f(y)}{\partial z}=0 \Rightarrow \phi^{\prime}(z)=\varepsilon z^{\varepsilon-1}$

If $\varepsilon>1$ then, there exist an integer $n$ such that $n=\varepsilon-1>0$. Indeed, the derivative of the function of technology is, $\phi^{\prime}(z)=(1+n) z^{n}$. Therefore, the previous function can be approximated by the series $\sum_{n=0}^{+\infty}(1+n) z^{n}$. Given that the general term of the series $\sum_{p=0}^{+\infty} z^{p}$ is $z^{p}$ and converges to $1 / 1-z$ since $|z|<1$. Then $\sum_{n=0}^{+\infty}(1+n) z^{n}$ is the derivative of the previous serial where $p=1+n$. Thus, its general term is $p z^{p-1}$ and can be approximated by the series $\sum_{n=0}^{+\infty}(1+n) z^{n}$ which converges to $1 /(1-z)^{2}$. Therefore, we have $\phi^{\prime}(\mathrm{z}) \simeq 1 /(1-\mathrm{z})^{2}$. Indeed, $\phi(\mathrm{z})=1 / 1-\mathrm{z}<\infty$.

Consequently, if $0<z<1$, the technology chosen by the firms $N_{2}$ is $\phi(\mathrm{z})=1 / 1-\mathrm{z}<\infty$ which is an increasing convex function.

In contrast, if $z=1$ then, accord ing to the assumptions of the model, we have $\phi^{\prime}(1)=\delta$ thus $\phi(z)=\delta z=\delta$ which corresponds to the technology chosen by the firms $N_{1}$, a constant function not linked to the index of technology. Consequently, the technology used by the firms $N_{1}$ is $\phi$ $(z)=\delta^{8}$.

Proof of the growth rates

$$
\begin{aligned}
& \frac{\partial H}{\partial c_{1}}=0 \Rightarrow c_{1}^{-\sigma_{1}}-B\left(\gamma_{1}^{-1}\right)^{\xi} c_{1}^{{ }^{\varsigma-1}}=\lambda_{1}, \\
& \frac{\partial H}{\partial c_{2}}=0 \Rightarrow \alpha c_{2}^{\alpha\left(1-\sigma_{2}\right)-1} v^{\beta\left(1-\sigma_{2}\right)}=\lambda_{2},
\end{aligned}
$$

\footnotetext{
${ }^{8}$ Because of its improvements absence through time, it is a pollution-augmenting technological change [Bovenberg-Smulders (1995)]. It generates an increase in pollution through time in contrast to the technology used by the firms $N_{2}$ which therefore, is a pollution-reducing technology. The lower the technology index is, the more efficient the corresponding production is both in its level and its quality (ecological) aspects
}

$\frac{\partial H}{\partial v}=0 \Rightarrow \beta c_{2}^{\beta\left(1-\sigma_{2}\right)-1} c_{2}^{\alpha\left(1-\sigma_{2}\right)}=\lambda_{3} \theta_{h}(1-z)^{-1} h$,

Therefore we have

$$
\begin{gathered}
-\sigma_{2} \frac{c_{1}}{c_{1}}-(\varsigma-1) \frac{c_{1}}{c_{1}}=\frac{\lambda_{1}}{\lambda_{1}}, \\
{\left[\alpha\left(1-\sigma_{2}\right)-1\right] \frac{c_{2}}{c_{2}}-\beta\left(1-\sigma_{2}\right) \frac{\stackrel{v}{v}}{v} \frac{\grave{\lambda}_{2}}{\lambda_{2}},} \\
\alpha\left(1-\sigma_{2}\right) \frac{c_{2}}{c_{2}}-\left[1-\beta\left(1-\sigma_{2}\right)\right] \frac{\stackrel{v}{v}}{v}=\frac{\lambda_{3}}{\lambda_{3}}+\frac{\grave{h}}{h}
\end{gathered}
$$

Where

$$
\begin{gathered}
g_{1}=\frac{c_{1}}{c_{1}}, \quad g_{2}=\frac{c_{2}}{c_{2}} \\
g_{v}=\frac{v}{v}
\end{gathered}
$$

The factor prices are

$$
\begin{gathered}
\dot{\circ}_{1}=\rho \lambda_{1}-\frac{\partial H}{\partial k_{1}} \text { then } \\
\frac{\dot{\lambda}_{1}}{\lambda_{1}}=\rho-\delta \mu_{1}\left[\delta \mu_{1}^{2} \psi\right]^{-1}=\rho-\left[\mu_{1} \psi\right]^{-1} \\
\dot{\lambda}_{2}=\rho \lambda_{2}-\frac{\partial H}{\partial k_{2}} \text { then } \frac{\dot{\lambda}_{2}}{\lambda_{2}}=\rho-\mu_{2}(1-z)^{-1} k_{2}^{\mu_{2}-1} \\
\dot{\circ}_{3}=\rho \lambda_{3}-\frac{\partial H}{\partial h} \text { then } \frac{\dot{\lambda}_{3}}{\lambda_{3}}=\rho-\theta_{h}(1-z)^{-1} v^{*}
\end{gathered}
$$

Where $v^{*}$ is the optimal demand of insurance Therefore we obtain

$$
g_{1}=\frac{1}{\sigma_{1}+\varsigma-1}\left(\rho-\frac{1}{\mu_{1} \psi}\right)
$$

$$
\begin{aligned}
& g_{2}=\frac{1-\beta\left(1-\sigma_{2}\right)}{\sigma_{2}}\left[\mu_{2}^{2}(1-z)^{-1 / \mu_{2}}\left(\frac{\alpha \gamma_{2}}{G^{*}}\right)^{1-\mu_{2} / \mu_{2}}-\rho\right] \\
& g_{v}=\frac{1-\beta\left(1-\sigma_{2}\right)}{\sigma_{2}}\left[\mu_{2}^{2}(1-z)^{-1 / \mu 2}\left(\frac{\alpha \gamma_{2}}{G^{*}}\right)^{1-\mu 2 / \mu 2}-\rho\right] \\
& -\left(\frac{\mu_{2}}{1-z}\right)\left[\left(\frac{\alpha \gamma_{2}}{(1-z) \mu_{2} G^{*}}\right)\right]^{1-\mu 2 / \mu 2}
\end{aligned}
$$

Proof of the Optimal solution stability

If $g_{2}=g_{v}$ then we solution can be written such as a $(2,2)$ matrix i.e

$\mathrm{M}$ 


\begin{tabular}{|c|c|}
\hline$\frac{1}{\sigma_{1}+\varsigma-1}$ & $-\frac{1}{\mu_{1} \psi}$ \\
\hline$\frac{1-\beta\left(1-\sigma_{2}\right)}{\sigma_{2}}$ & {$\left[\frac{1-\beta\left(1-\sigma_{2}\right)}{\sigma_{2}}\right] \mu_{2}^{2}$} \\
& $(1-z)^{-1 / \mu_{2}}\left(\frac{\alpha \gamma_{2}}{G^{*}}\right)^{1-\mu_{2} / \mu_{2}}$ \\
\hline
\end{tabular}

Indeed the characteristic polynomial, $P_{M}(\lambda)$ is the following matrix

\begin{tabular}{|l|c|}
\hline$\frac{1}{\sigma_{1}+\varsigma-1}-\lambda$ & $-\frac{1}{\mu_{1} \psi}$ \\
\hline$\frac{1-\beta\left(1-\sigma_{2}\right)}{\sigma_{2}}$ & {$\left[\frac{1-\beta\left(1-\sigma_{2}\right)}{\sigma_{2}}\right] \mu_{2}^{2}(1-z)^{-1 / \mu_{2}}$} \\
& $\left(\frac{\alpha \gamma_{2}}{G^{*}}\right)^{1-\mu_{2} / \mu_{2}}-\lambda$ \\
\hline
\end{tabular}

We obtained through the calculus that $P_{M}$ $(\lambda)=\lambda^{2}+(a+b) \lambda+a b$

Where

$$
\begin{gathered}
\frac{1}{\sigma_{1}+\varsigma-1} \\
\mathrm{~b}=\left[\frac{1-\beta\left(1-\sigma_{2}\right)}{\sigma_{2}}\right] \mu_{2}^{2}(1-z)^{-1 / \mu_{2}}\left(\frac{\alpha \gamma_{2}}{G^{*}}\right)^{1-\mu_{2} / \mu_{2}}
\end{gathered}
$$

Therefore $\Delta=(\mathrm{a}+\mathrm{b})^{2}-4 \mathrm{ab}=(\mathrm{a}-\mathrm{b})^{2}>0$

Thus, there exist two eigenvalues which are

$$
\begin{aligned}
& \lambda^{\prime}=\frac{1}{\sigma_{1}+\varsigma-1}>0 \\
& \lambda "=\left[\frac{1-\beta\left(1-\sigma_{2}\right)}{\sigma_{2}}\right] \mu_{2}^{2}(1-z)^{-1 / \mu_{2}}\left(\frac{\alpha \gamma_{2}}{G^{*}}\right)^{1-\mu_{2} / \mu_{2}}>0 \\
& \text { Trace } \quad\left(P_{M}(\lambda)\right)=\lambda^{\prime}+\quad \lambda^{\prime \prime}=\frac{1}{\sigma_{1}+\varsigma-1}+
\end{aligned}
$$$$
\left[\frac{1-\beta\left(1-\sigma_{2}\right)}{\sigma_{2}}\right] \mu_{2}^{2}(1-z)^{-1 / \mu_{2}}\left(\frac{\alpha \gamma_{2}}{G^{*}}\right)^{1-\mu_{2} / \mu_{2}}>0
$$$$
\operatorname{Det}\left(P_{M}(\lambda)\right)=\lambda \lambda^{\prime}{ }^{\prime}=
$$$$
\frac{1}{\sigma_{1}+\varsigma-1}
$$$$
\left[\frac{1-\beta\left(1-\sigma_{2}\right)}{\sigma_{2}}\right] \mu_{2}^{2}(1-z)^{-1 / \mu_{2}}\left(\frac{\alpha \gamma_{2}}{G^{*}}\right)^{1-\mu_{2} / \mu_{2}}>0
$$

Consequently, the solution exists and is optimal

Proof: setting the pollution evolution to zero i.e $x\left(y_{2}\right)=0$ yields the equilibrium per-capita stock of capital leading to pollution eradication $k_{2}{ }^{*}$ such as $k_{2}^{*} \approx\left[\left(\frac{\mu_{2}}{\alpha \gamma_{2}-1}\right)(1-z) G^{*}\right]^{1 / \mu_{2}}$

because $\left|\alpha \gamma_{2}-1\right|<\alpha \gamma_{2}$ then $1 /\left|\alpha \gamma_{2}-1\right| \geq 1 / \alpha \gamma_{2}$ which yields $\left(\frac{\mu_{2}}{\alpha \gamma_{2}-1}\right) \geq\left(\frac{\mu_{2}}{\alpha \gamma_{2}}\right) \quad$ then we have $\left[\left(\frac{\mu_{2}}{\alpha \gamma_{2}-1}\right)(1-z) G^{*}\right]^{1 / \mu_{2}} \succ k_{2}^{*} \geq\left[\left(\frac{\mu_{2}}{\alpha \gamma_{2}}\right)(1-z) G^{*}\right]^{1 / \mu_{2}}$ . Indeed we can approximate per-capita capital stock such as $k_{2}^{*}=\left[\left(\frac{\mu_{2}}{\alpha \gamma_{2}}\right)(1-z) G^{*}\right]^{1 / \mu_{2}}$. Therefore, since the two previous conditions on capital equilibrium stock $k_{1}{ }^{*}$ and revenues from taxes on emissions $G^{*}$ are filled, the social planner's intervention has higher probabilities of success.

First, to prove the production threshold's expression, we follow Stockey (1998) in assuming $z=\left(y^{*} / y_{2}\right)^{\mu_{2}}$ where $0<\mu_{2}<1$. Indeed, the threshold of the level of production is ${ }^{9}$, $y^{*}=z^{1 / \mu_{2}} y_{2}$ which leads to $y^{*}=z^{1 / \mu_{2}}(1-z)^{-1} k_{2}^{* \mu_{2}}$ then $y^{*}=z^{1 / \mu_{2}}\left(\mu_{2} / \alpha \gamma_{2}\right) G^{*}$ We have $0<\mu_{2} \prec 1$ and $0<z<1$ indeed, $z^{1 / \mu_{2}}$ converges to 0 and thus $y^{*} \leqslant y_{2}$

Second, to express the wage rate income threshold, we know that $w^{L}<w^{*} \leq w^{H}$ then replacing the wage rate incomes by their respective value leads to $\delta \gamma_{1} k_{1}^{* \mu_{1}}<w^{*} \leq \gamma_{2}(1-z)^{-1} k_{2}^{*} \mu_{2} \quad$ replacing once more per-capita capital equilibrium stocks by their respective values, yields $w^{*}=\gamma_{2}\left(\mu_{2} / \alpha \gamma_{2}\right) G^{*}$ finally replacing $G^{*}$ by its value, gives the wage rate income threshold expression written above.

Third: to express human capital threshold level, we assume that basic human capital growth rate moves such as $h_{0}(t) / h_{0}(t)=u \delta$. Therefore our aim is to make $u \delta h_{0}$ converge to $h^{*}$ where $h^{*} / h^{*}$ already converge to $h(t) / h(t)$ and therefore we have, ${ }^{*} / h^{*} \approx \theta_{h} v^{*}(1-z)^{-1}$ and $h^{*}$ is the learning by doing effect on labour productivity, $v^{*}$ is the insurance equilibrium computed above.Indeed, 。*

$h / h^{*}=\left[\beta \theta_{h} \mu_{2} / \alpha(1-z)\right] G^{*}$ and following Lucas (1988), $u \in[0,1]$ is the fraction of time an agent spends in the production process in order to increase his labour productivity. The full time of each agent is normalized to 1 and $u \preccurlyeq \theta_{h}$ i.e productivity acquired older through the production process is lower than the one acquired in the education sector earlier by skilled labour or the actual labour

\footnotetext{
${ }^{9}$ the threshold of production is given since the inverse of the elasticity of substitution equals 1
} 
force of the firm, $N_{2}$. Costly education is assumed to be more efficient than learning by doing ${ }^{\mathrm{i}}$.

Therefore we have $\left(u+\theta_{h}\right) h^{*}=\left[\beta \theta_{h} \mu_{2} / \alpha(1-z)\right] G^{*}$ Indeed $h^{*}=\left[\beta \theta_{h} \mu_{2} / \alpha(1-z)\left(u+\theta_{h}\right)\right] G^{*}$

\section{REFERENCES}

[1] Keefer, P. and Hhemani, S., 2012, Do informed citizens receive more...or pay more ? the impact of radio on the government distribution of public health benefits, Policy Research working paper_; no. WPS 5952

[2] Loeadholm, C., 2002, Small firm dynamics: Evidence from Africa and Latin America, Small Business Economics, 18 (3), 227-242

[3] Burki, A. and Terrel, D., 1998, Measuring production efficiency of small firms in Pakistan, World Development, 26 (1), 155-169

[4] Mbaku, J., 2007, "Corruption and development", School of economics, Weber State University

[5] Morgan, A. L., 1998, Corruption: causes, consequences and policy implications, A literature Review, $W P N^{\circ} 9$

[6] Qian, Rong, 2012, Why do some countries default more often than others? the role of institutions, Policy Research working paper ; no. WPS 5993

[7] Banuri, S. and Eckel, C.; 2012, Experiments in culture and corruption, Policy Research working paper ; no. WPS 6064

[8] Bardhan, P., 1996, "The Economics of Corruption in Less Developed Countries: A Review of Issues," Center for International and Development Economics Research, Working Paper No. C96-064. University of California, Berkeley: February.
[9] Klitgaard (1988)

[10] Kaufmann, S., “Anti-Corruption Strategies,” 1997: 15

[11] Porter and Van-der-Linde (1995), Toward a New Conception of the Environment-Competitiveness Relationship, 1995, Journal of Economic Perspectives, Vol.9, 97-118

[12] Aghion, P. and Howitt, P., 1992, A Model of Growth through Creative Destruction, Econometrica, 60, 323-51

[13] Aghion, P. and Howitt, P., 1998, La Théorie de la Croissance Endogène, Econometrica, 60, 323-51

[14] Stockey, N., 1998, Are There Limits to Growth?, International Economic Review, 39, 1-31

[15] Bovenberg, A. Lans and S. Smulders, Environmental quality and pollution-augmenting technological change in a two-sector endogenous growth model, Journal of Public Economics, 57, 1995, 369-391

[16] Brock, W. and Taylor, S., 2004, The Green Solow Model, Working Paper, $\mathrm{N}^{\circ} 2004-16$

[17] Stiglitz, Joseph, 1974, Growth with Axhaustible Natural Resources: Efficient and Optimal Growth Paths, The Review of Economic Studies, Vol. 41, 123-137

[18] Goklany, Indur, M., 2009, Have increases in population, affluence and technology worsened human and environmental well-being?, The Electronic Journal of Sustainable Development, 1, (3)

[19] Goklany, Indur, M., 1995, Strategies to enhance adaptability: Technological Change, Sustainable Growth and Free Trade, Kluwer Academic Publishers, 30, 427-449

[20] Eicher, T., 1996, Interaction between human capital and technological change, Review of Economic Studies, 63, 127-144

[21] Solow, R., 1956, A contribution to the theory of economic growth, Quarterly Journal of Economics, 70, 65-94

\footnotetext{
${ }^{\mathrm{i}}$ This point of view is highly discussed in microeconomic concerning human capital investment where for some authors edu cation is a filter or a signal and only the experienced at work is efficient.
} 